\title{
Cause of death in patients diagnosed with esophageal cancer in Sweden: a population-based study
}

\author{
Shao-Hua Xie ${ }^{1}$, Karl Wahlin ${ }^{1}$ and Jesper Lagergren ${ }^{1,2}$ \\ ${ }^{1}$ Upper Gastrointestinal Surgery, Department of Molecular Medicine and Surgery, Karolinska Institutet, Karolinska University \\ Hospital, Sweden \\ 2 Division of Cancer Studies, King's College London, United Kingdom \\ Correspondence to: Shao-Hua Xie, email: shaohva.xie@ki.se
}

Keywords: esophageal cancer; prognosis; mortality; cause of death; Sweden

Received: December 21, $2016 \quad$ Accepted: January 27, 2017 Published: February 11, 2017

Copyright: Xie et al. This is an open-access article distributed under the terms of the Creative Commons Attribution License 3.0 (CC BY 3.0), which permits unrestricted use, distribution, and reproduction in any medium, provided the original author and source are credited.

\section{ABSTRACT}

Background: Esophageal cancer carries a poor prognosis with an overall 5-year survival of less than $\mathbf{2 0 \%}$. However, the causes of death in patients with esophageal cancer have not been well described.

Methods: This nationwide, population-based cohort study included 18229 esophageal cancer patients who were diagnosed between 1961 and 2014 in Sweden. We assessed the distribution of main causes of death in patients with esophageal cancer and used competing-risks regression to compare the cause-specific risks of death across sexes, ages at diagnosis, and calendar periods of diagnosis.

Results: A total of 16938 (92.9\%) patients died during follow-up. Esophageal cancer accounted for $\mathbf{7 9 . 5 \%}$ of all reported deaths. Other major causes of death were non-esophageal cancers $(9.8 \%)$, ischemic heart disease or cerebrovascular disease $(4.2 \%)$ and respiratory diseases (1.3\%). Female patients had a lower risk of death from esophageal cancer (sub-hazard ratio [SHR] $=0.90,95 \%$ confidence interval [CI]: $0.87,0.94)$, which was more pronounced in patients with squamous cell carcinoma (SHR=0.85, 95\% CI: 0.81, 0.89). Risks of death from esophageal cancer and other cancers in patients who were diagnosed in more recent calendar periods were lower than in those diagnosed in earlier periods.

Conclusions: Patients diagnosed with esophageal cancer are more likely to die from this cancer than from other causes. However, these patients also face considerable risk of death from other cancers, ischemic heart disease, cerebrovascular disease, and respiratory diseases. These common causes of death should be taken into consideration in esophageal cancer management.

\section{INTRODUCTION}

Esophageal cancer is the eighth most common type of malignancy and the sixth leading cause of cancer death globally. $[1,2]$ There are two main histological types, i.e., esophageal squamous cell carcinoma (ESCC) and esophageal adenocarcinoma (EAC). Although ESCC accounts for approximately $90 \%$ of all cases of esophageal cancer worldwide, the incidence of EAC has been rapidly increasing in many regions, including Europe and North America, during the past four decades. [3, 4]

Esophageal cancer carries a poor prognosis with the overall 5-year survival following diagnosis lower than
20\%. [3-5] Understanding the specific causes of death in patients with this cancer is essential for improving the prognosis, but reliable estimates of these causes are largely lacking. Previous studies have indicated a considerable proportion of deaths attributable to non-cancer conditions in patients with esophageal cancer. [6-8] A high incidence of secondary malignancies in patients with esophageal cancer has also been noted. $[9,10]$ However, these were mainly observations based on relatively small groups of patients, and the causes of death in patients with esophageal cancer have not been well described.

To improve our understanding of the excess mortality in relation to esophageal cancer, we performed 
Table 1: Basic characteristics of all patients with esophageal cancer diagnosed in Sweden in 1961-2014, number $(\%)$.

\begin{tabular}{|l|l|l|l|}
\hline Characteristic & Squamous cell carcinoma & Adenocarcinoma & Total esophageal cancer \\
\hline Total & $10230(100.0)$ & $5140(100.0)$ & $18229(100.0)$ \\
\hline Sex & & & \\
\hline Male & $6763(66.1)$ & $4173(81.2)$ & $12867(70.6)$ \\
\hline Female & $3467(33.9)$ & $967(18.8)$ & $5362(29.4)$ \\
\hline Age at diagnosis, years & \multicolumn{5}{l|}{} \\
\hline$<50$ & $319(3.1)$ & $212(4.1)$ & $630(3.5)$ \\
\hline $50-59$ & $1378(13.5)$ & $717(13.9)$ & $2390(13.1)$ \\
\hline $60-69$ & $3189(31.2)$ & $1491(29.0)$ & $5344(29.3)$ \\
\hline $70-79$ & $3541(34.6)$ & $1622(31.6)$ & $6161(33.8)$ \\
\hline$\geq 80$ & $1803(17.6)$ & $1098(21.4)$ & $3704(20.3)$ \\
\hline Mean (standard deviation) & $69.6(10.4)$ & $69.8(11.2)$ & $70.1(10.8)$ \\
\hline Calendar period of diagnosis & \multicolumn{3}{l|}{} \\
\hline $1961-1970$ & $1564(15.3)$ & $231(4.5 \%)$ & $2376(13.0)$ \\
\hline $1971-1980$ & $1885(18.4)$ & $390(7.6)$ & $2818(15.5)$ \\
\hline $1981-1990$ & $2190(21.4)$ & $484(9.4)$ & $3070(16.8)$ \\
\hline $1991-2000$ & $2099(20.5)$ & $1004(19.5)$ & $3631(19.9)$ \\
\hline $2001-2014$ & $2492(24.4)$ & $3031(59.0)$ & $6334(34.7)$ \\
\hline Length of follow-up, years & $7429(72.6)$ & $3419(66.5)$ & $12838(70.4)$ \\
\hline$\leq 1$ & $2180(21.3)$ & $1356(26.4)$ & $4050(22.2)$ \\
\hline $1-5$ & $621(6.1)$ & $365(7.1)$ & $1341(7.4)$ \\
\hline$>5$ & \multicolumn{5}{|l|}{} \\
\hline
\end{tabular}

this population-based study to assess causes of death in patients diagnosed with esophageal cancer in Sweden over more than 5 decades. A competing-risks model was applied to compare cause-specific risks of death by sex, age at diagnosis, and calendar period of diagnosis.

\section{RESULTS}

\section{Patients}

This study included 18229 patients diagnosed with esophageal cancer, including 10230 (56\%) cases of ESCC, 5140 (28\%) cases of EAC, and the remaining cases were diagnosed with other $(n=2189,12 \%)$ or unspecified ( $n=670,4 \%$ ) histology. Males accounted for $81.2 \%$ of all EAC cases and $66.1 \%$ of all ESCC cases. The mean (standard deviation) age at diagnosis was 70.1 (10.8) years. More detailed distribution of all cases of esophageal cancer by sex, age at diagnosis, calendar period of diagnosis, and follow-up time is presented in Table 1.

\section{Causes of death}

Table 2 shows the distribution of cause-specific deaths in patients diagnosed with esophageal cancer by duration of follow-up. A total of 16938 (92.9\%) patients died during follow-up, among which 12487 (73.8\% of all deaths) occurred within 1 year of diagnosis. The median survival following diagnosis estimated from 16 499 patients with complete follow-up was 179 days (95\% confidence interval [CI]: 175, 183), which did not differ by histological type (ESCC, 185 days, $95 \%$ CI: 180, 191; EAC, 194 days, 95\% CI: 185, 204). The median survival time in female patients (192 days, $95 \%$ CI: 184, 201) was slightly longer than in males (175 days, $95 \% \mathrm{CI}$ : 170 , 179).

Esophageal cancer was the most common cause of death; nearly three quarters of all patients diagnosed with esophageal cancer $(73.9 \%, n=13474)$ died from this disease. Non-esophageal cancers were the second most common cause of death, accounting for 1657 (9.8\%) of all deaths. Among all reported deaths, 712 (4.2\%) were due to ischemic heart disease or cerebrovascular disease, and $226(1.3 \%)$ were due to respiratory diseases. Deaths from causes other than esophageal cancer were more common 
Table 2: Causes of death by duration of follow-up in patients with esophageal cancer in Sweden in 1961-2014.

\begin{tabular}{|c|c|c|c|}
\hline \multirow[b]{2}{*}{ Mortality status } & \multicolumn{3}{|c|}{ Duration of follow-up } \\
\hline & $\begin{array}{c}\leq 1 \text { year } \\
\text { Number }(\%)\end{array}$ & $\begin{array}{c}1-5 \text { years } \\
\text { Number }(\%)\end{array}$ & $\begin{array}{c}>5 \text { years } \\
\text { Number }(\%)\end{array}$ \\
\hline Total $^{*}$ & 18229 & 5391 & 1341 \\
\hline Alive throughout follow-up ${ }^{\dagger \ddagger}$ & $351(1.9)$ & $415(7.7)$ & $525(39.1)$ \\
\hline All deaths $*$ & $12487(68.5)$ & $3635(67.4)$ & $816(60.9)$ \\
\hline \multicolumn{4}{|l|}{ Cause-specific death $*$} \\
\hline Esophageal cancer & $10415(57.1)$ & $2849(52.8)$ & $210(15.7)$ \\
\hline Cancers other than esophageal cancer & $1091(6.0)$ & $385(7.1)$ & $181(13.5)$ \\
\hline Infectious and parasitic diseases & $21(0.1)$ & $11(0.2)$ & $7(0.5)$ \\
\hline Diseases of the respiratory system & $113(0.6)$ & $49(0.9)$ & $64(4.8)$ \\
\hline Chronic obstructive pulmonary disease & $52(0.3)$ & $21(0.4)$ & $29(2.2)$ \\
\hline Influenza and pneumonia & $43(0.2)$ & $22(0.4)$ & $24(1.8)$ \\
\hline Ischemic heart disease & $320(1.8)$ & $127(2.4)$ & $128(9.5)$ \\
\hline Cerebrovascular disease & $60(0.3)$ & $41(0.8)$ & $36(2.7)$ \\
\hline Diabetes & $23(0.1)$ & $1(<0.1)$ & $2(0.1)$ \\
\hline Dementia and Alzheimer's disease & $2(0.1)$ & $1(<0.1)$ & $17(1.3)$ \\
\hline External causes, including suicide & $14(0.1)$ & $9(0.2)$ & $16(1.2)$ \\
\hline Suicide & $6(<0.1)$ & $2(<0.1)$ & $2(0.1)$ \\
\hline Other specified & $428(2.3)$ & $162(3.0)$ & $155(11.6)$ \\
\hline
\end{tabular}

* Number of patients alive at the beginning of the follow-up window.

$\uparrow$ Patients alive at the beginning of the follow-up window who did not die during the specified period of follow-up.

$\$$ Percentage of all patients alive at the beginning of the follow-up window.

in patients with longer follow-up (longer survival). For example, $13.5 \%$ of all patients who were followed up for over 5 years died from non-esophageal cancers, while $6.0 \%$ of patients with $\leq 1$ year follow-up died from these cancers (Table 2).

Among all deaths from non-esophageal cancers, 982 (59.3) were due to cancers of digestive organs, 155 (9.4\%) due to cancers of the lip, oral cavity, and pharynx, and 145 (8.8\%) due to lung cancer (Table 3). Gastric cancer was the single most common cause $(n=851,51.4 \%)$ of death from non-esophageal cancers (Table 3).

Stratified analyses by histological type showed that compared with patients with ESCC, patients diagnosed with EAC were less likely to die from esophageal cancer but more likely to die from other cancers (Table 4).

\section{Competing-risks regression}

The estimated sub-hazard ratios (SHRs) and their 95\% CIs of cause-specific death within 5 years following a diagnosis of esophageal cancer from competing-risks regression are presented in Table 5. Female patients had lower risks of death from all listed causes, although the reduced risk was only statistically significant for death from esophageal cancer (SHR $=0.90,95 \%$ CI: 0.87, 0.94). Risks of death from esophageal cancer and ischemic heart disease or cerebrovascular disease increased with age, suggesting a monotonic age-response association. Patients who were diagnosed in more recent calendar periods had lower risk of death form esophageal cancer compared with those diagnosed in earlier periods; patients diagnosed in 2001-2014 had a 30\% decreased risk of death from esophageal cancer compared to those diagnosed in 1961-1971 (SHR $=0.71,95 \%$ CI: 0.67, 0.75). We also observed a reduced risk of death from other cancers in patients diagnosed in later calendar periods, although it reached the level of statistical significance only for the period 1981-1990 compared with the earliest period 1961$1970($ SHR $=0.80,95 \%$ CI: 0.67, 0.91).

We performed stratified analyses by histological type for deaths from esophageal cancer and nonesophageal cancers, but not by other variables due to the limited number of deaths from other causes. The results are shown in Table 6. The reduced risk of death from esophageal cancer in female patients was limited to those diagnosed with ESCC (SHR $=0.85,95 \%$ CI: 0.81, 0.89) and not those with EAC (SHR $=0.97,95 \%$ CI: 0.88, 1.06). There was an increased risk of death from esophageal cancer with older age in patients diagnosed with both 
Table 3: Deaths from non-esophageal cancers in patients diagnosed with esophageal cancer in Sweden in $1961-2014$.

\begin{tabular}{|c|c|c|c|}
\hline Sites & $\begin{array}{l}\text { Total esophageal cancer } \\
\text { Number }(\%)\end{array}$ & $\begin{array}{l}\text { Squamous cell carcinoma } \\
\text { Number }(\%)\end{array}$ & $\begin{array}{l}\text { Adenocarcinoma } \\
\text { Number }(\%) \\
\end{array}$ \\
\hline Total & $1657(100.0)$ & $686(100.0)$ & $694(100.0)$ \\
\hline Lip, oral cavity, and pharynx & $155(9.4)$ & $134(19.5)$ & $2(0.3)$ \\
\hline Digestive organs $^{\dagger}$ & $982(59.3)$ & $275(40.1)$ & $577(83.1)$ \\
\hline Stomach & $851(51.4)$ & $216(31.5)$ & $535(77.1)$ \\
\hline Colon, rectum, and anus & $44(2.7)$ & $21(3.1)$ & $14(2.0)$ \\
\hline Liver and biliary passages & $25(1.5)$ & $10(1.5)$ & $6(0.9)$ \\
\hline Pancreas & $42(2.5)$ & $24(3.5)$ & $9(1.3)$ \\
\hline Lung (incl. trachea and bronchus) & $145(8.8)$ & $92(13.4)$ & $22(3.2)$ \\
\hline Breast & $25(1.5)$ & $11(1.6)$ & $7(1.0)$ \\
\hline Uterus & $7(0.4)$ & $5(0.7)$ & $1(0.1)$ \\
\hline Ovary & $5(0.3)$ & $3(0.4)$ & $1(0.1)$ \\
\hline Prostate & $52(3.1)$ & $15(2.2)$ & $23(3.3)$ \\
\hline Testis & $2(0.1)$ & $1(0.1)$ & $0(0.0)$ \\
\hline Bladder & $8(0.5)$ & $3(0.4)$ & $1(0.1)$ \\
\hline Kidney & $14(0.8)$ & $7(1.0)$ & $4(0.6)$ \\
\hline Thyroid & $9(0.5)$ & $5(0.7)$ & $0(0.0)$ \\
\hline Hodgkin lymphoma & $1(0.1)$ & $1(0.1)$ & $0(0.0)$ \\
\hline Non-Hodgkin lymphoma & $13(0.8)$ & $4(0.6)$ & $5(0.7)$ \\
\hline Leukemia & $12(0.7)$ & $6(0.9)$ & $4(0.6)$ \\
\hline Other and unspecified & $227(13.7)$ & $124(18.1)$ & $47(6.8)$ \\
\hline
\end{tabular}

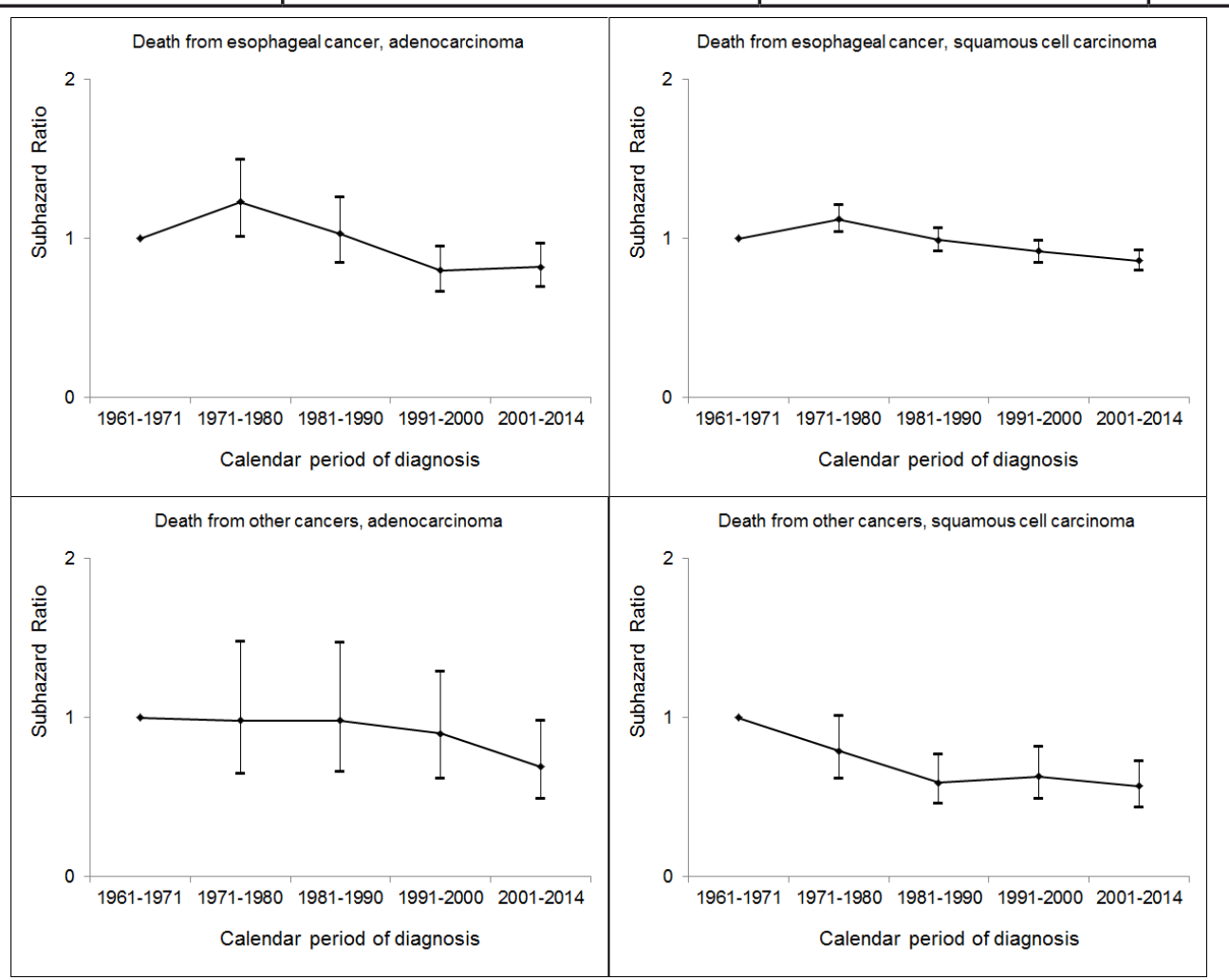

Figure 1: Risks of death from esophageal cancer and other cancers in patients diagnosed with adenocarcinoma and squamous cell carcinoma of the esophagus as estimated as sub-hazard ratios (95\% confidence intervals) from competing-risks regression. 
Table 4: Distribution of causes of death by duration of follow-up in patients with esophageal adenocarcinoma and esophageal squamous cell carcinoma in Sweden, 1961-2014.

\begin{tabular}{|c|c|c|c|c|c|c|}
\hline \multirow{2}{*}{ Mortality status } & \multicolumn{3}{|c|}{ Adenocarcinoma } & \multicolumn{3}{|c|}{ Squamous cell carcinoma } \\
\hline & $\leq 1$ year & 1-5 years & $>5$ years & $\leq 1$ year & $1-5$ years & $>5$ years \\
\hline Number of individuals at risk ${ }^{*}$ & 5140 & 1721 & 365 & 10230 & 2801 & 621 \\
\hline Alive throughout follow-up, $\mathrm{n}(\%)^{\dagger}$ & $185(3.6)$ & $202(11.7)$ & $206(56.4)$ & $118(1.2)$ & $120(4.3)$ & $156(25.1)$ \\
\hline All deaths, $n(\%)$ & $3234(62.9)$ & $1154(67.1)$ & $159(43.6)$ & $7311(71.5)$ & $2060(73.5)$ & $465(74.9)$ \\
\hline \multicolumn{7}{|l|}{ Cause-specific death, $\mathrm{n}(\%)^{ \pm}$} \\
\hline Esophageal cancer & $2532(49.3)$ & $856(49.7)$ & $44(12.1)$ & $6308(61.7)$ & $1723(61.5)$ & $129(20.8)$ \\
\hline Cancers other than esophageal cancer & $450(8.8)$ & $197(11.4)$ & $47(12.9)$ & $458(4.5)$ & $133(4.7)$ & $95(15.3)$ \\
\hline Infectious and parasitic diseases & $8(0.2)$ & $6(0.3)$ & $2(0.5)$ & $8(0.1)$ & $4(0.1)$ & $2(0.3)$ \\
\hline Diseases of the respiratory system & $20(0.4)$ & $8(0.5)$ & $9(2.5)$ & $70(0.7)$ & $27(1.0)$ & $37(6.0)$ \\
\hline Chronic obstructive pulmonary disease & $13(0.3)$ & $3(0.2)$ & $4(1.1)$ & $27(0.3)$ & $12(0.4)$ & $19(3.1)$ \\
\hline Influenza and pneumonia & $3(0.1)$ & $3(0.2)$ & $3(0.8)$ & $31(0.3)$ & $12(0.4)$ & $16(2.6)$ \\
\hline Ischemic heart disease & $81(1.6)$ & $28(1.6)$ & $19(5.2)$ & $182(1.8)$ & $69(2.5)$ & $83(13.4)$ \\
\hline Cerebrovascular disease & $15(0.3)$ & $8(0.5)$ & $7(1.9)$ & $34(0.3)$ & $20(0.7)$ & $16(2.6)$ \\
\hline Diabetes & $10(0.2)$ & $0(0.0)$ & $0(0.0)$ & $10(0.1)$ & $0(0.0)$ & $2(0.3)$ \\
\hline Dementia and Alzheimer's disease & $0(0.0)$ & $0(0.0)$ & $1(0.3)$ & $2(<0.1)$ & $0(0.0)$ & $13(2.1)$ \\
\hline External causes, including suicide & $9(0.2)$ & $2(0.1)$ & $2(0.5)$ & $3(<0.1)$ & $3(0.1)$ & $8(1.3)$ \\
\hline Suicide & $6(0.1)$ & $0(0.0)$ & $0(0.0)$ & $0(0.0)$ & $1(<0.1)$ & $1(0.2)$ \\
\hline Other specified & $109(2.1)$ & $49(2.8)$ & $28(7.7)$ & $236(2.3)$ & $81(2.9)$ & $80(12.9)$ \\
\hline
\end{tabular}

* Number of patients alive at the beginning of the follow-up window.

$\uparrow$ Patients alive at the beginning of the follow-up window who did not die during the specified period of follow-up.

\$ Percentage of all patients alive at the beginning of the follow-up window.

ESCC and EAC. Regardless of histological type, patients diagnosed with esophageal cancer in later calendar periods had lower risks of death from both esophageal cancer and other cancers, compared with those diagnosed in earlier periods (Figure 1).

\section{Cox regression}

The hazard ratios from the Cox regression were similar to the SHRs from competing-risks regression, except for that the observed associations from Cox regression were generally stronger than those from competing-risks regression (Supplementary Tables 1 and 2).

\section{DISCUSSION}

This study revealed that although patients diagnosed with esophageal cancer were more likely to die from esophageal cancer than other causes, there were also other major causes of death, including non-esophageal cancers, ischemic heart disease, cerebrovascular disease and respiratory diseases. Female patients had a lower risk of death from esophageal cancer than male patients, which was more pronounced in patients with adenocarcinoma. Risks of death from esophageal cancer and other cancers were lower in patients diagnosed in more recent calendar periods compared to those diagnosed in earlier periods.

To the best of our knowledge, this study is the first population-based study and has the largest sample size on causes of death in patients with esophageal cancer. The complete nationwide coverage and high accuracy of the Swedish Cancer Register and the Swedish Cause of Death Register ensured the representativeness of the findings and minimized selection bias. In addition, the competing-risks regression employed in this study posits a model for the sub-hazard function of a failure event in the presence of competing failure events, i.e. risk of death from a specific cause of death of interest in the presence of other competing causes in the context of mortality data. On the contrary, the alternative Cox regression treats competing causes of death as censored events, but such events are in fact distinct from standard censorings due to loss to follow-up, merely obstructing researchers from observing the events of interest. [11, 12] Although both methods yielded similar estimates in this study, findings from ordinary Cox regression need to be interpreted with more caution, given the possibly biased estimates 
Table 5: Subhazard ratios with $95 \%$ confidence intervals of cause-specific death within 5 years of follow-up by sex, age at diagnosis, and calendar period of diagnosis, from competing-risks regression.

\begin{tabular}{|c|c|c|c|c|c|}
\hline \multirow[b]{2}{*}{ Characteristic } & \multicolumn{5}{|l|}{ Causes of death } \\
\hline & Esophageal cancer & Non-esophageal cancers & \begin{tabular}{|l|} 
Ischemic heart disease \\
or cerebrovascular \\
disease
\end{tabular} & $\begin{array}{l}\text { Respiratory } \\
\text { diseases }\end{array}$ & Other causes \\
\hline \multicolumn{6}{|l|}{ Sex } \\
\hline Male & 1.00 (reference) & 1.00 (reference) & 1.00 (reference) & 1.00 (reference) & 1.00 (reference) \\
\hline Female & $0.90(0.87,0.94)$ & $0.93(0.82,1.04)$ & $0.90(0.75,1.08)$ & $0.82(0.57,1.18)$ & $0.98(0.83,1.16)$ \\
\hline \multicolumn{6}{|c|}{ Age at diagnosis, years } \\
\hline$<50$ & 1.00 (reference) & 1.00 (reference) & 1.00 (reference) & 1.00 (reference) & 1.00 (reference) \\
\hline $50-59$ & $1.25(1.13,1.39)$ & $0.77(0.57,1.05)$ & $5.24(1.27,21.66)$ & $0.67(0.26,1.73)$ & $0.67(0.41,1.11)$ \\
\hline $60-69$ & $1.26(1.14,1.39)$ & $0.99(0.75,1.30)$ & $6.74(1.67,27.23)$ & $0.65(0.27,1.54)$ & $0.79(0.50,1.25)$ \\
\hline $70-79$ & $1.34(1.21,1.48)$ & $0.96(0.73,1.27)$ & $11.44(2.85,45.92)$ & $1.15(0.50,2.65)$ & $1.24(0.79,1.93)$ \\
\hline$\geq 80$ & $1.66(1.50,1.85)$ & $0.83(0.62,1.10)$ & $16.26(4.05,65.37)$ & $1.33(0.56,3.14)$ & $1.83(1.17,2.87)$ \\
\hline \multicolumn{6}{|c|}{ Calendar period of diagnosis } \\
\hline $1961-1970$ & 1.00 (reference) & 1.00 (reference) & 1.00 (reference) & 1.00 (reference) & 1.00 (reference) \\
\hline 1971-1980 & $1.08(1.02,1.16)$ & $0.94(0.78,1.13)$ & $0.60(0.43,0.84)$ & $0.54(0.25,1.15)$ & $0.57(0.41,0.79)$ \\
\hline 1981-1990 & $0.96(0.91,1.03)$ & $0.80(0.67,0.97)$ & $1.20(0.91,1.58)$ & $1.86(1.06,3.28)$ & $0.72(0.54,0.97)$ \\
\hline $1991-2000$ & $0.80(0.75,0.85)$ & $0.91(0.76,1.08)$ & $0.97(0.73,1.28)$ & $1.30(0.73,2.32)$ & $1.14(0.88,1.47)$ \\
\hline 2001-2014 & $0.71(0.67,0.75)$ & $0.91(0.78,1.07)$ & $0.69(0.53,0.90)$ & $1.28(0.73,2.22)$ & $1.10(0.87,1.40)$ \\
\hline
\end{tabular}

of cause-specific risk of death by failing to account for competing causes. [11-13] As they were performed in previous causes-of-death analyses, [14-16] we analyzed the primary causes of death only from death records and did not consider other contributing causes due to methodological constraints, although the assumption that each death is caused by only one disease is debatable. [17] In addition, despite the relatively large sample size compared with previous studies, this study did not have adequate statistical power for all subgroup analyses on non-cancer causes of death by histological type. Analysis by stage was not within the scope of this study.

The literature examining causes of death in patients diagnosed with esophageal cancer is limited. Current knowledge is based on hospital-based studies with hundreds or fewer patients in the selected group who underwent esophagectomy. [6-8, 18] These studies showed that esophageal cancer was the leading cause of death in patients diagnosed with this cancer, and other major causes of death were non-esophageal cancers, cardiovascular disease and respiratory diseases. It has also been suggested that gastric, head and neck, and lung cancers were the most common causes of death among deaths caused by non-esophageal malignancies. These observations are consistent with the findings of the present study. However, no previous studies have assessed the temporal trends in the cause-specific risks of death or had the statistical power to conduct robust subgroup analyses.

This study suggests that esophageal cancer remains the predominant cause of death in patients diagnosed with this cancer, particularly within the first year of diagnosis. A large study from the Surveillance, Epidemiology, and End Results Program (SEER) database in the United States has shown that the esophageal cancer-specific survival was around only $10 \%$ in patients with metastatic esophageal cancer 2 years after diagnosis, whereas it was over $20 \%$ in patients with localized esophageal cancer 5 years after diagnosis. [19] Therefore, death directly from esophageal cancer may be more relevant to patients who are diagnosed at advanced stages, while patients who have curative therapies also face considerable risk of death from this cancer due to postoperative complications or tumor recurrence. The observed decreased risk of death from esophageal cancer in patients diagnosed with esophageal cancer in recent calendar periods might be attributable to a better selection of patients suitable for curative surgery, increased use of neoadjuvant therapies, as well as increased centralization of the treatment. [4, 20] Despite all efforts to improve the diagnostic procedures and therapy, the overall 5-year survival following diagnosis in patients with esophageal cancer remains lower than $20 \%$ even in Western societies. Tumor stage at diagnosis remains by far the strongest prognostic factor. [3-5] Thus, earlier tumor detection at a more curable stage would likely improve the prognosis in patients with esophageal cancer. Upper endoscopy provides an opportunity of early detection of esophageal cancer or its precursors, i.e., squamous-cell dysplasia for ESCC and Barrett's 
Table 6: Subhazard ratios with $95 \%$ confidence interval of death from esophageal cancer and non-esophageal cancers within 5 years of follow-up by histological type, from competing-risks regression

\begin{tabular}{|c|c|c|c|c|}
\hline \multirow{2}{*}{ Characteristic } & \multicolumn{2}{|c|}{ Adenocarcinoma } & \multicolumn{2}{|c|}{ Squamous cell carcinoma } \\
\hline & Esophageal cancer & Non-esophageal cancers & Esophageal cancer & Non-esophageal cancers \\
\hline \multicolumn{5}{|l|}{ Sex } \\
\hline Male & 1.00 (reference) & 1.00 (reference) & 1.00 (reference) & 1.00 (reference) \\
\hline Female & $0.97(0.88,1.06)$ & $1.19(0.98,1.45)$ & $0.85(0.81,0.89)$ & $0.93(0.78,1.12)$ \\
\hline \multicolumn{5}{|c|}{ Age at diagnosis, years } \\
\hline$<50$ & 1.00 (reference) & 1.00 (reference) & 1.00 (reference) & 1.00 (reference) \\
\hline $50-59$ & $1.19(0.99,1.43)$ & $0.68(0.45,1.04)$ & $1.13(0.99,1.29)$ & $1.16(0.65,2.04)$ \\
\hline $60-69$ & $1.09(0.91,1.30)$ & $0.96(0.66,1.40)$ & $1.18(1.03,1.34)$ & $1.43(0.84,2.45)$ \\
\hline $70-79$ & $1.26(1.06,1.50)$ & $0.85(0.57,1.23)$ & $1.23(1.08,1.40)$ & $1.46(0.85,2.49)$ \\
\hline$\geq 80$ & $1.66(1.38,1.99)$ & $0.72(0.48,1.06)$ & $1.49(1.30,1.70)$ & $1.11(0.63,1.95)$ \\
\hline \multicolumn{5}{|c|}{ Calendar period of diagnosis } \\
\hline $1961-1970$ & 1.00 (reference) & 1.00 (reference) & 1.00 (reference) & 1.00 (reference) \\
\hline $1971-1980$ & $1.23(1.01,1.50)$ & $0.98(0.65,1.48)$ & $1.12(1.04,1.21)$ & $0.79(0.62,1.01)$ \\
\hline $1981-1990$ & $1.03(0.85,1.26)$ & $0.98(0.66,1.47)$ & $0.99(0.92,1.07)$ & $0.59(0.46,0.77)$ \\
\hline $1991-2000$ & $0.80(0.67,0.95)$ & $0.90(0.62,1.29)$ & $0.92(0.85,0.99)$ & $0.63(0.49,0.82)$ \\
\hline 2001-2014 & $0.82(0.70,0.97)$ & $0.69(0.49,0.98)$ & $0.86(0.80,0.93)$ & $0.57(0.44,0.73)$ \\
\hline
\end{tabular}

esophagus with dysplasia for EAC, although a universal strategy in the general population is not feasible due to the low incidence of esophageal cancer. [21, 22] Identifying high-risk individuals based on their risk factor profiles is a promising approach, which requires reliable tools of risk stratification in the population. A few risk prediction models combining information on readily identifiable risk factors have been developed for the selection of individuals with high risk of esophageal cancer, but remain to be further validated. [23, 24]

The present study shows considerable risk of death from non-esophageal cancers, particularly from cancers of the digestive organs, head and neck, and lung. These results are in line with analyses from the SEER database in the United States which revealed increased risks of secondary malignancies, including cancers of oral and pharynx, stomach, and lung, following a diagnosis of esophageal cancer. [9, 10] These findings may be explained by shared risk factors for esophageal and nonesophageal malignancies, e.g. tobacco smoking, alcohol abuse and inappropriate diet, but are also possibly related to treatments administered to patients with esophageal cancer, e.g. irradiative effects from radiotherapy. The observed lower risk of death from esophageal cancer in female patients than in males was more pronounced in patients with ESCC and is consistent with some previous evidence. [19] However, the underlying mechanisms for a protective role of the female sex are unclear. It has been hypothesized that sex hormones may play a role in both the development and prognosis of esophageal cancer, but existing evidence remains inconclusive and warrants further research. [25]

Ischemic heart disease, cerebrovascular disease and respiratory diseases are increasingly common causes of death in the general population, especially in an era where infectious diseases are replaced by chronic diseases. $[26,27]$ Patients with esophageal cancer may be more vulnerable to death from these conditions due to increased rates of immunodeficiency, malnutrition and systematic inflammation. [28, 29] Modifications of lifestyle risk factors, e.g. smoking cessation, physical activity, and dietary habits, have been suggested to be associated with reduced all-cause and certain cause-specific mortality. [30-32] However, benefits of such lifestyle changes on the prognosis in patients with esophageal cancer are less clear. [29] More studies, preferably well-designed randomized controlled trials with sufficient statistical power, are needed to explore and assess effective interventions aiming at reducing overall and cause-specific mortality in patients with esophageal cancer.

In summary, this nationwide and population-based study reveals that patients diagnosed with esophageal cancer are more likely to die from this cancer than from any other causes. However, these patients also face considerable risk of death from other causes, particularly from non-esophageal cancers, ischemic heart disease, cerebrovascular disease and respiratory diseases. More efforts in identifying high-risk individuals for early detection, refining the selection of patients for tailored treatment, exploring new treatment strategies, and 
assessing effective lifestyle interventions, are needed to improve the overall and cause-specific survival in patients diagnosed with esophageal cancer.

\section{MATERIALS AND METHODS}

\section{Study design and population}

This study was a population-based cohort study. The study population consisted of all patients who were diagnosed with esophageal cancer (International Classification of Diseases, $7^{\text {th }}$ edition [ICD-7] code: 150 ) in Sweden between $1^{\text {st }}$ January 1961 and $31^{\text {st }}$ December 2014. These patients were identified from the Swedish Cancer Registry, which has a 98\% nationwide coverage of esophageal cancer and $96 \%$ coverage of all cancers. $[33,34]$ We obtained information on causes of death of the cohort members through linkage to the Swedish Cause of Death Register with the unique personal identity number. The Cause of Death Register covers all deaths of persons who were registered in Sweden in the year they died, and the non-reporting rate was estimated as lower than 1\%. [35] All participants were followed up from the date of esophageal cancer diagnosis until the date of death or the end of the study ( $31^{\text {st }}$ December 2014), whichever occurred first. This study was approved by the Regional Ethical Review Board in Stockholm, Sweden (Protocol Number: 2010/727-31/2).

\section{Outcome ascertainment}

We described the distribution of major cause of death, which accounts for over $95 \%$ of all deaths in the study population. The specific ICD codes for different causes of death are listed in Supplementary Table 3. All causes of death were further categorized into the following five groups: (1) esophageal cancer, (2) other (non-esophageal) cancers, (3) ischemic heart disease or cerebrovascular disease, (3) diseases of the respiratory system and (5) other causes. Only the primary causes of death, i.e. the disease or injury initiating the train of events leading directly to death, or the circumstances of the accident or violence producing the fatal injury, were analyzed in this study.

\section{Statistical analysis}

We assessed the distribution of primary major causes of death in patients with esophageal cancer by categories of duration of follow-up ( $\leq 1,1-5$, or $>5$ years), which was calculated as the date of diagnosis to the end of follow-up. We used competing-risks regression embedded in the statistical software STATA (version 14; http://www.stata.com/features/overview/competing-risksregression/) to compare the cause-specific risks of death in patients with different characteristics. The competingrisks regression is based on the method of Fine and Gray and estimates the cause-specific SHRs in the presence of competing risks, i.e., deaths from other causes. $[11,36]$ Variables included in the model were sex (male or female), age at diagnosis ( $<50,50-59,60-69,70-79$ or $\geq 80$ years $)$, and calendar period of diagnosis (1961-1970, 1971-1980, 1981-1990, 1991-2000 or 2001-2014). For comparison purposes, we also performed Cox proportional hazard regression where competing events were considered as censored observations. We further performed stratified analyses by histological type. All statistical analyses except for the competing-risks regression were performed using IBM SPSS Statistics for Windows, version 23 (Armonk, NY: IBM Corp.).

\section{CONFLICTS OF INTEREST}

The authors declare no conflicts of interest.

\section{GRANT SUPPORT}

This study was supported by the Swedish Research Council [521-2014-2536] and the Swedish Cancer Society [CAN 2015/460]. The funding bodies had no role in the study design, the collection, analysis, and interpretation of data, or the writing of the article and the decision to submit it for publication.

\section{REFERENCES}

1. Ferlay J, Soerjomataram I, Ervik M, Dikshit R, Eser S, Mathers C, Rebelo M, Parkin DM, Forman D, Bray F. Cancer incidence and mortality worldwide: sources, methods and major patterns in GLOBOCAN 2012. Lyon, France: International Agency for Research on Cancer; 2013.

2. Global Burden of Disease Cancer C, Fitzmaurice C, Dicker D, Pain A, Hamavid H, Moradi-Lakeh M, MacIntyre MF, Allen C, Hansen G, Woodbrook R, Wolfe C, Hamadeh RR, Moore A, et al. The Global Burden of Cancer 2013. JAMA Oncol. 2015; 1: 505-27.

3. Rustgi AK, El-Serag HB. Esophageal carcinoma. N Engl J Med. 2014; 371: 2499-509.

4. Lagergren J, Lagergren P. Recent developments in esophageal adenocarcinoma. CA Cancer J Clin. 2013; 63: 232-48.

5. De Angelis R, Sant M, Coleman MP, Francisci S, Baili P, Pierannunzio D, Trama A, Visser O, Brenner H, Ardanaz E, Bielska-Lasota M, Engholm G, Nennecke A, et al. Cancer survival in Europe 1999-2007 by country and age: results of EUROCARE--5-a population-based study. Lancet Oncol. 2014; 15: 23-34.

6. Kauppi J, Gockel I, Rantanen T, Hansen T, Ristimaki A, 
Lang H, Sihvo E, Rasanen J, Junginger T, Salo JA. Cause of death during long-term follow-up for superficial esophageal adenocarcinoma. Ann Surg Oncol. 2013; 20: 2428-33.

7. Kakuta T, Kosugi S, Kanda T, Ishikawa T, Hanyu T, Suzuki T, Wakai T. Prognostic factors and causes of death in patients cured of esophageal cancer. Ann Surg Oncol. 2014; 21: 1749-55.

8. Sato Y, Motoyama S, Maruyama K, Okuyama M, Ogawa J. A second malignancy is the major cause of death among thoracic squamous cell esophageal cancer patients negative for lymph node involvement. J Am Coll Surg. 2005; 201: 188-93.

9. Chuang SC, Hashibe M, Scelo G, Brewster DH, Pukkala E, Friis S, Tracey E, Weiderpass E, Hemminki K, Tamaro S, Chia KS, Pompe-Kirn V, Kliewer EV, et al. Risk of second primary cancer among esophageal cancer patients: a pooled analysis of 13 cancer registries. Cancer Epidemiol Biomarkers Prev. 2008; 17: 1543-9.

10. Zhu G, Chen Y, Zhu Z, Lu L, Bi X, Deng Q, Chen X, Su H, Liu Y, Guo H, Zheng T, Yu H, Zhang Y. Risk of second primary cancer after treatment for esophageal cancer: a pooled analysis of nine cancer registries. Dis Esophagus. 2012; 25: 505-11.

11. Dignam JJ, Zhang Q, Kocherginsky M. The use and interpretation of competing risks regression models. Clin Cancer Res. 2012; 18: 2301-8.

12. Kim HT. Cumulative incidence in competing risks data and competing risks regression analysis. Clin Cancer Res. 2007; 13: 559-65.

13. Berry SD, Ngo L, Samelson EJ, Kiel DP. Competing risk of death: an important consideration in studies of older adults. J Am Geriatr Soc. 2010; 58: 783-7.

14. Epstein MM, Edgren G, Rider JR, Mucci LA, Adami HO. Temporal trends in cause of death among Swedish and US men with prostate cancer. J Natl Cancer Inst. 2012; 104: 1335-42.

15. Thompson S, James M, Wiebe N, Hemmelgarn B, Manns B, Klarenbach S, Tonelli M, Alberta Kidney Disease N. Cause of Death in Patients with Reduced Kidney Function. J Am Soc Nephrol. 2015; 26: 2504-11.

16. Prospective Studies C, Whitlock G, Lewington S, Sherliker P, Clarke R, Emberson J, Halsey J, Qizilbash N, Collins R, Peto R. Body-mass index and cause-specific mortality in 900000 adults: collaborative analyses of 57 prospective studies. Lancet. 2009; 373: 1083-96.

17. Moreno-Betancur M, Sadaoui H, Piffaretti C, Rey G. Survival Analysis with Multiple Causes of Death: Extending the Competing Risks Model. Epidemiology. 2017; 28: 12-9.

18. Cilley RE, Strodel WE, Peterson RO. Cause of death in carcinoma of the esophagus. Am J Gastroenterol. 1989; 84: 147-9.

19. Bohanes P, Yang D, Chhibar RS, Labonte MJ, Winder T, Ning Y, Gerger A, Benhaim L, Paez D, Wakatsuki T,
Loupakis F, El-Khoueiry R, Zhang W, et al. Influence of sex on the survival of patients with esophageal cancer. J Clin Oncol. 2012; 30: 2265-72.

20. Rouvelas I, Zeng W, Lindblad M, Viklund P, Ye W, Lagergren J. Survival after surgery for oesophageal cancer: a population-based study. Lancet Oncol. 2005; 6: 864-70.

21. Lao-Sirieix P, Fitzgerald RC. Screening for oesophageal cancer. Nat Rev Clin Oncol. 2012; 9: 278-87.

22. Sami SS, Ragunath K, Iyer PG. Screening for Barrett's esophagus and esophageal adenocarcinoma: rationale, recent progress, challenges, and future directions. Clin Gastroenterol Hepatol. 2015; 13: 623-34.

23. Xie SH, Lagergren J. A model for predicting individuals' absolute risk of esophageal adenocarcinoma: Moving toward tailored screening and prevention. Int $\mathrm{J}$ Cancer. 2016; 138: 2813-9.

24. Thrift AP, Kendall BJ, Pandeya N, Whiteman DC. A model to determine absolute risk for esophageal adenocarcinoma. Clin Gastroenterol Hepatol. 2013; 11: 138-44 e2.

25. Xie SH, Lagergren J. The Male Predominance in Esophageal Adenocarcinoma. Clin Gastroenterol Hepatol. 2016; 14: 338-47 e1.

26. Mari-Dell'Olmo M, Gotsens M, Palencia L, Burstrom B, Corman D, Costa G, Deboosere P, Diez E, DominguezBerjon F, Dzurova D, Gandarillas A, Hoffmann R, Kovacs $\mathrm{K}$, et al. Socioeconomic inequalities in cause-specific mortality in 15 European cities. J Epidemiol Community Health. 2015; 69: 432-41.

27. Mortality GBD, Causes of Death C. Global, regional, and national age-sex specific all-cause and cause-specific mortality for 240 causes of death, 1990-2013: a systematic analysis for the Global Burden of Disease Study 2013. Lancet. 2015; 385: 117-71.

28. Backemar L, Lagergren P, Johar A, Lagergren J. Impact of co-morbidity on mortality after oesophageal cancer surgery. Br J Surg. 2015; 102: 1097-105.

29. Anandavadivelan P, Lagergren P. Cachexia in patients with oesophageal cancer. Nat Rev Clin Oncol. 2016; 13: 185-98.

30. Cao Y, Kenfield S, Song Y, Rosner B, Qiu W, Sesso HD, Gaziano JM, Ma J. Cigarette smoking cessation and total and cause-specific mortality: a 22-year follow-up study among US male physicians. Arch Intern Med. 2011; 171: 1956-9.

31. Friedenreich CM, Wang Q, Neilson HK, Kopciuk KA, McGregor SE, Courneya KS. Physical Activity and Survival After Prostate Cancer. Eur Urol. 2016.

32. Wang DD, Li Y, Chiuve SE, Stampfer MJ, Manson JE, Rimm EB, Willett WC, Hu FB. Association of Specific Dietary Fats With Total and Cause-Specific Mortality. JAMA Intern Med. 2016.

33. Barlow L, Westergren K, Holmberg L, Talback M. The completeness of the Swedish Cancer Register: a sample survey for year 1998. Acta Oncol. 2009; 48: 27-33.

34. Lindblad M, Ye W, Lindgren A, Lagergren J. Disparities in 
the classification of esophageal and cardia adenocarcinomas and their influence on reported incidence rates. Ann Surg. 2006; 243: 479-85.

35. Socialstyrelsen S. Dödsorsaksstatistik historik, produktionsmetoder och tillförlitlighet. Sverige Socialstyrelsen. 2010.
36. Fine JP, Gray RJ. A proportional hazards model for the subdistribution of a competing risk. J Am Stat Assoc. 1999; 94: 496-509. 